\title{
ISSN 2302-8734
}

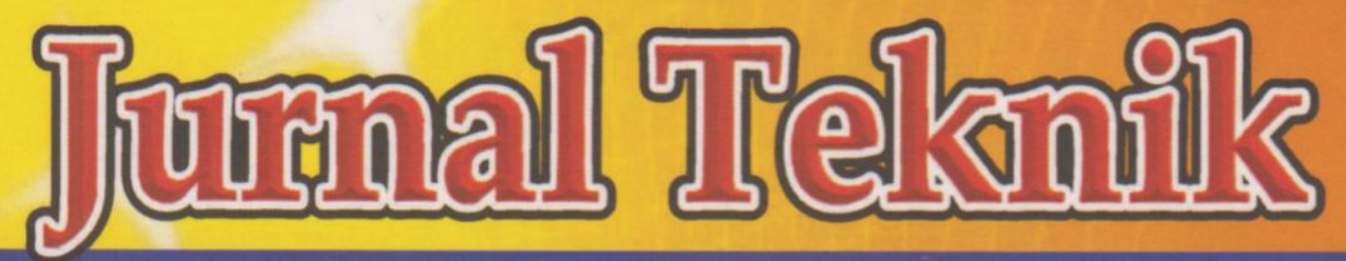

TEKNIK INFORMATIKA - TEKNIK MESIN - TEKNIK SIPIL - TEKNIK ELEKTRO - TEKNIK INDUSTRI

\section{Jurnal Teknik, Vol.3 No. 1, Agustus 2014}

RANCANG BANGUN SISTEM INFORMASI PENJUALAN MOBIL BERBASIS WEB STUDI KASUS PT. RAJAWALI SENTOSA

Elfa Fitria, Renold Sirayan

ANALISA PERANCANGAN SISTEM PENJUALAN ONLINE PADA

PT. INDOTAICHEN TEXTILE INDUSTRY

Irfan nasrullah

RANCANG BANGUN SISTEM INFORMASI PERPUSTAKAAN BERBASIS WEB

PADA SD NEGERI PORIS PLAWAD 7 TANGERANG

Muhammad Jonni

ANALISIS SISTEM PEMBELIAN BARANG MATERIAL PADA

PT. KARUNACON INDOTAMA

Rohmat Taufiq, Predi Dermawan

IMPLEMENTASI LOGIKA FUZZY DALAM PENENTUAN POLA PENGGUNAAN

ENERGI LISTRIK PADA SUATU GEDUNG BERDASARKAN HASIL AUDIT

Rahma Farah Ningrum

MINIMALISASI DEFECT PRODUK GRANITE TILE PADA PROSES SORTING \& POLISHING

DENGAN PENDEKATAN ROOT CAUSE ANALYSIS (RCA)

Bambang Suhardi Waluyo, Tri Widodo

ANALISA BEBAN DINAMIK PADA GEDUNG BERTINGKAT SEDERHANA DAN TINGGI

UNIVERSITAS MUHAMMADIYAH TANGERANG

Almufid, Saiful Haq

SISTEM PROTEKSI DARI PEMBANGKIT SAMPAI KONSUMEN

Andrie D.Nurdin, Bayu Purnomo

PERANCANGAN KONTROL OTOMATIS MESIN MIXER PENGADUK BAHAN

PADA PERUSAHAAN MAKANAN DAN MINUMAN

Sumardi, Lis Handoko

ANALISA TATA LETAK PABRIK UNTUK MEMINIMALISASI MATERLAL HANDLING PADA PABRIK SHEET METAL DENGAN SOFTWARE PROMODEL

Sri Lestari

EVALUASI KUALITAS PELAYANAN PENGUJIAN KENDARAAN BERMOTOR DENGAN METODE SERVQUAL

Tri Widodo

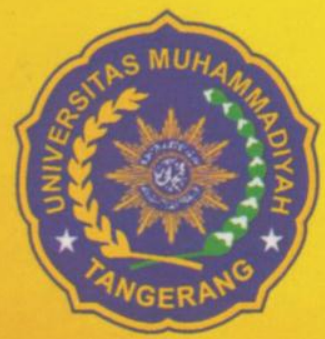

Fakultas Teknik 


\title{
Susunan Redaksi Jurnal Teknik Fakultas Teknik - Universitas Muhammadiyah Tangerang
}

\author{
Pelindung \\ : H. Achmad Badawi, S.Pd., SE., MM. (Rektor UMT) \\ Penanggung Jawab : Ir. Saiful Haq (Dekan Teknik) \\ Pembina Redaksi $\quad$ : 1. Rohmat Taufik, ST., M.Kom. \\ 2. Drs. H. Syamsul Bahri, MSi. \\ Pimpinan Redaksi : Drs. Ir. Sumardi Sadi, MT. \\ Redaktur Pelaksana : Mahpud, M.Kom \\ Dewan Redaksi \\ : 1. M. Jonni, M.Kom. \\ 2. Vienka Rahmanita, MT. \\ 3. Ir. Bayu Purnomo \\ 4. Elfa Fitria, S.Kom, M.Eng. \\ 5. Bambang Suhardi, W, ST, MT. \\ 6. Yafid Efendi, ST, MT. \\ Mitra Bestari \\ : 1. Prof. Dr. Aris Gumilar \\ 2. Dr. Ir. Doddy Hermiyono, DEA. \\ 3. Nur Fajar Yanta, MSc.
}

Alamat:

J. Perintis Kemerdekaan I No. 33 Cikokol Tangerang 5537198

Telp. : 02151374916 


\section{DAFTAR ISI}

1. Rancang Bangun Sistem Informasi Penjualan Mobil Berbasis Web Studi Kasus PT. Rajawali Sentosa - 1

Elfa Fitria, Renold Sirayan

2. Analisa Perancangan Sistem Penjualan Online Pada PT. Indotaichen Textile Industry -9

Irfan Nasrullah

3. Rancang Bangun Sistem Informasi Perpustakaan Berbasis Web Pada Sd Negeri Poris Plawad 7 Tangerang - 19

Muhammad Jonni

4. Analisis Sistem Pembelian Barang Material Pada PT. Karunacon Indotama 36

Rohmat Taufiq, Predi Dermawan

5. Implementasi Logika Fuzzy Dalam Penentuan Pola Penggunaan Energi Listrik Pada Suatu Gedung Berdasarkan Hasil Audit Energi - 44

Rahma Farah Ningrum, S.Kom, M.Kom.

6. Minimalisasi Defect Produk Granite Tile Pada Proses Sorting \& Polishing Dengan Pendekatan Root Cause Analysis (RCA) (Studi Kasus di PT. Niro Ceramic Nasional Indonesia, Bogor-Jawa Barat) - 53

Bambang Suhardi Waluyo, MT \& Tri Widodo, MT

7. Analisa Beban Dinamik Pada Gedung Bertingkat Sederhana dan Tinggi Universitas Muhammadiyah Tangerang - 68

Almufid, Saiful Haq

8. Sistem Proteksi dari Pembangkit Sampai Konsumen - 80

Andrie D. Nurdin, Bayu Purnomo

9. Perancangan Kontrol Otomatis Mesin Mixer Pengaduk Bahan Pada Perusahaan Makanan dan Minuman - 91

Sumardi, Lis Handoko

10. Analisa Tata Letak Pabrik Untuk Meminimalisasi Material Handling Pada Pabrik Sheet Metal Dengan Software Promodel - 106

Sri Lestari

11. Evaluasi Kualitas Pelayanan Pengujian Kendaraan Bermotor Dengan Metode Servqual - 111

Tri Widodo, MT 


\title{
ANALISA PERANCANGAN SISTEM PENJUALAN ONLINE PADA PT. INDOTAICHEN TEXTILE INDUSTRY
}

\author{
Irfan Nasrullah \\ Program Study Teknik Informatika Fakultas Teknik \\ Universitas Muhammadiyah Tangerang \\ E-mail: pengembara82@yahoo.co.id
}

\begin{abstract}
ABSTRAK
Tujuan dari penulis dengan judul Analisa Perancangan Sistem Penjualan Online pada PT.Indotaichen Textile Industry di Tangerang yang sedang berjalan dan menerapkan sistem informasi penjualan secara online dalam pemesanan product, data custumer, harga product, dan informasi pengiriman yang didasari pada analisis sistem yang sedang berjalan.

Adapun masalah yang dihadapi ialah ketika jangkauan dalam melakukan pemasaran yang masih kurang luas untuk mewakili semua produk yang dimiliki oleh perusahaan secara detail. Sehingga kurang dapat berkompetensi dengan pesaing lain yang telah memanfaatkan E-commerce dalam kegiatan usahanya.

Dengan adanya sistem berbasis web ini, yang sudah terkoneksi dengan database, tentunya akan sangat mempermudah pengolahan data untuk melakukan kegiatan transaksi pemesanan dan penjualan, karena setiap informasi yang akan diberikan kepada konsumen bisa lebih cepat, akurat dan tentunya dengan biaya yang sangat murah.
\end{abstract}

Kata Kunci : analisis penjualan, perancangan penjualan, e-commerce

\section{PENDAHULUAN}

\subsection{Latar Belakang Masalah}

Perkembangan teknologi yang semakin pesat membuat setiap perusahaan harus dapat beradaptasi dan melakukan suatu evaluasi terhadap kegiatan administrasi maupun kegiatan operasional perusahaannya. Pertumbuhan teknologi yang terjadi dari tahun ke tahun semakin meningkat khususnya teknologi komputer. Komputer merupakan aset bagi perusahaan sekarang ini karena dapat membantu dalam segala bidang pekerjaan seperi bidang kedokteran, militer, komunikasi, dll. Adanya komputer semua informasi yang dibutuhkan oleh perusahaan dapat dicari dengan mudah, cepat, dan akurat. Informasi yang didapat meru- pakan sumber daya yang sangat penting khususnya dalam pengambilan keputusan manajemen.

Kebutuhan akan teknologi komputer dan internet yang semakin kompleks sekarang ini membuat setiap perusahaan memanfaatkan teknologi ini dengan sebaik-baiknya agar perusahaan dapat bersaing sehat dengan para pesaingnya. Persaingan yang terjadi dalam dunia bisnis membutuhkan informasi yang terkini sehingga diperlukan alat pengolah data. Data yang didapatkan harus dikelola terlebih dahulu, agar menjadi informasi bermanfaat bagi yang menerimanya. PT. Indotaichen Textile Industry merupakan salah satu perusahaan yang turut me- 
manfaatkan teknologi komputer dan informasi.

PT. Indotaichen Textile Industry yang merupakan suatu perusahaan bergerak di bidang industri tekstil yang memproduksi kain. PT. Indotaichen Textile Industry dalam kegiatan administrasi maupun kegiatan operasionalnya masih bersifat manual seperti sistem personalia, sistem penggajian, sistem pembelian, sistem persediaan, dan sistem penjualan. Pengolahan data yang dilakukan secara manual, dan menimbulkan beberapa masalah dalam perusahaan, seperti keterlambatan informasi sehingga dapat menyebabkan ketidakakuratan data.

Sistem penjualan yang terjadi di PT. Indotaichen Textile Industry memiliki masalah yang cukup kompleks. Oleh sebab itu, PT. Indotaichen Textile Industry perlu membuat "Analisa Perancangan Sistem Penjualan Online Pada PT. Indotaichen Textile Industry" yang dapat mempermudah dalam kegiatan administrasi dan kegiatan operasional perusahaan. Penjualan Online merupakan salah satu cara yang paling praktis dan efisien untuk menjalankan sebuah usaha dengan secepat mungkin.

\subsection{Batasan Masalah}

Dalam penelitian ini tidak akan membahas semua kegiatan yang ada di PT. Indotaichen Textile Industry tetapi hanya sebatas pada beberapa sistem sebagai berikut:

1. Pelayanan Informasi

Pada sistem informasi akan membahas mengenai tentang profil dari PT. Indotaichen Textile Industry sampai dengan bagaimana cara proses dari kain greige sampai menjadi kain jadi.

2. Penjualan

Pada sistem penjualan akan membahas mengenai pelanggan memberikan data barang ke dalam sistem, yang berisi nama barang, harga beli barang dan jumlah barang yang dimasukkan, yang selanjutnya akan diproses di dalam sistem informasi penjualan. Kemudian sistem informasi penjualan akan menghasilkan keluaran yang berupa bukti transaksi yaitu nota hasil transaksi penjualan yang akan diberikan kepada pelanggan, beserta laporan penjualan barang secara keseluruhan.

3. Perdagangan Melalui Perantara Pada sistem perdagangan melalui perantara akan membahas tentang bagaimana proses pengiriman berlangsung mulai dari status pengiriman sampai terkirimnya barang ke tangan pelanggan.

4. Pembayaran

Pada sistem pembayaran akan membahas tentang suatu pilihan pembayaran yang akan dipilih oleh buyer, yaitu dengan melalui bank menggunakan Letter of Credit dan transfer.

\subsection{Rumusan Masalah}

Seperti latar belakang yang telah diuraikan di atas, dapat dirumuskan permasalahan yang akan diteliti, antara lain sebagai berikut:

1. Bagaimana sistem penjualan pada PT. Indotaichen Textile Industy ?

2. Bagaimana metode penjualan pada PT. Indotaichen Textile Industy ?

3. Bagaimana merancang sistem penjualan online yang sesuai pada PT. Indotaichen Textile Industry?

\subsection{Tujuan Penelitian}

Adapun tujuan dari rancangan program aplikasi penjualan PT. Indotaichen Textile Industry ini adalah sebagai berikut :

1. Membantu bagian marketing dan billing untuk mempermudah dalam kegiatan administrasi dan kegiatan operasional perusahaan.

2. Membantu perusahaan untuk melakukan penjualanan secara online yang mana hal tersebut 
dapat memperkenalkan perusahaan di dunia international.

3. Mencari sebuah kepercayaan kepada industry di bidang garment untuk menggunakan jasa PT. Indotaichen Textile Industry sebagai bahan dasar garment.

\subsection{Manfaat Penelitian}

Manfaat atau kegunaan dari Perancangan Sistem Penjualan Online aplikasi web penjualan PT. Indotaichen Textile Industry ini adalah sebagai berikut :

1. Mempermudah dan mempercepat dalam kegiatan administrasi maupun kegiatan operasional perusahaan.

2. Mempermudah mendapatkan informasi yang dibutuhkan dengan cepat, tepat waktu, dan akurat khususnya bagi manajer dalam pengambilan keputusan.

3. Mendapatkan kepercayaan dari setiap pelanggan yang berada di dalam maupun di luar negri.

\section{LANDASAN PEMIKIRAN}

\subsection{Pengertian sistem}

Menurut Raymond McLeod, Jr., George P.Schell diterjemahkan oleh Ali Akbar Yulianto (2010: 10), Sistem Informasi adalah suatu sistem virtual yang memungkinkan manajemen mengendalikan operasi sistem fisik perusahaan pada suatu jaringan kerja dari prosedur-prosedur yang saling berhubungan, berkumpul bersama-sama untuk melakukan suatu kegiatan atau untuk menyelesaikan suatu sasaran yang tertentu, dalam suatu urut-urtan operasi klerikal (tulis menulis) biasanya melibatkan beberapa orang didalam satu atau lebih departemen, yang diterapkan untuk menjamin penanganan yang seragam dari transaksi bisnis yang terjadi.

Menurut Kenneth E. Kendall diterjemahkan Thamir Abdul Hafedh AlHamdany, B.Sc., M.Sc (2010: 34) mendefinisikan sistem sebegai berikut, Sistem adalah kumpulan dari elemenelemen yang berinteraksi untuk mencapai suatu tujuan tertentu, dan memproses perubahan atau mentranformasikan input menjadi output.

\subsection{Pengertian Informasi}

Menurut McFadden dkk diterjemahkan oleh Agus Mulyanto (2010: 15) Informasi adalah data yang diolah menjadi sebuah bentuk yang berarti bagi penerimanya dan bermanfaat dalam pengambilan keputusan saat ini atau mendatang.

Munurut Barry E, diterjemahkan oleh Agus Mulyanto (2010: 15) informasi merupakan sesuatu yang menunjukan hasil pengolahan data yang diorganisasikan dan berguna kepada orang yang menerimanya.

Menurut Stephen A, Moscove dan Mark G, Simkin dalam bukunya Accounting Informatio System dan diterjemahkan oleh Agus Mulyanto (2010: 15) mengatakan informasi sebagai kenyataan atau bentuk-bentuk yang berguna yang dapat digunakan untuk pengambilan keputusan bisnis.

\subsection{Pengertian Sistem Informasi}

Menurut Kenneth E. Kendall dan Julie E. Kendall diterjemahkan Thamir Abdul Hafedh Al-Hamdany (2010: 3) Sistem Informasi adalah informasi yang telah terkomputersasi yang bekerja karena adanya interaksi antara manusia dan komputer yang telah diketahui bahwa informasi merupakan hal yang sangat penting bagi manajemen di dalam pengambilan keputusan, dan informasi diperoleh dari sistem informasi (information system) atau disebut juga dengan processing system atau information processing system atau information-genering system, yang didefirnisikan sebagai berikut: "Sistem informasi adalah suatu sistem didalam suatu organisasi yang mempertemukan kebutuhan pengolahan transakasi ha- 
rian, mendukung operasi, bersifat manajerial dan kegiatan strategi dari suatu organisasi dan menyediakan pihak luar tertentu dengan laporan-laporan yang diperlukan."

\subsection{Pengertian Penjualan}

Sistem penjualan adalah suatu kerangka kerja dari seluruh kegiatan transaksi penjualan yang dikoordinasikan untuk menghasilkan informasi yang dibutuhkan oleh manajemen.

Menurut Aliminsyah (2010: 245), penjualan dapat dijelaskan sebagai kemampuan suatu perusahaan untuk mengadakan transaksi barang dan jasajasa dengan biaya yang ditawarkan sesuai tujuan yang ingin dicapai.

Dari definisi di atas, maka dapat disimpulkan bahwa penjualan adalah suatu kegiatan pertukaran barang atau jasa yang melibatkan antara penyedia dengan pengguna yang akan melakukan transaksi pembayaran secara tunai ataupun kredit atau yang biasa kita sebut dengan transaksi.

Dalam suatu perusahaan maupun organisasi, penjualan merupakan proses yang penting untuk mendapatkan keuntungan yang maksimal.

Pada dasarnya kegiatan penjualan berawal dari langkah-langkah :

1. Menentukan tingkat harga dan persyaratan yang dirasa wajar bagi para konsumen.

2. Melakukan pengembangan atas produk dan jasa untuk memenuhi kebutuhan atau keinginan konsumen.

3. Memilih atau menentukan secara tetap sistem saluran distribusi agar barang dan jasa yang dihasilkan mudah didapat oleh para konsumen.

4. Menentukan cara-cara promosi dan memilih media yang digunakan.

Penjualan merupakan kegiatan yang penting didalam perusahaan, karena penjualan adalah aktivitas untuk mendapatkan penghasilan secara langsung.

Penjualan juga merupakan suatu proses berpindahnya suatu hak atas barang atau jasa untuk mendapatkan sumber daya lainnya seperti kas atau janji untuk membayar kas (suatu piutang). Secara Umum penjualan dapat dibedakan menjadi 2 macam, yaitu:

1. Penjualan secara tunai.

Didalam penjualan tunai, barang atau jasa baru diserahkan oleh perusahaan kepada pembeli jika perusahaan telah menerima pembayaran dari pembeli. Dokumendokumen yang digunakan dalam penjualan tunai adalah faktur penjualan tunai dan bukti penerimaan kas.

2. Penjualan secara kredit.

Didalam penjualan kredit, jika order dari perusahaan telah dipenuhi dengan pengiriman barang atau penyerahan jasa, untuk jangka waktu tertentu pembeli memiliki piutang kepada perusahaan.

Konsep penjualan mengatakan bahwa konsumen jika diabaikan biasanya tidak akan membeli produk suatu organisasi (perusahaan) dalam jumlah yang cukup. Oleh karena itu perusahaan harus melakukan usaha penjualan dan promosi.

\subsection{Konsep Penjualan}

Konsep Penjualan mengatakan bahwa konsumen jika diabaikan biasanya tidak akan membeli produk suatu organisasi (perusahaan) dalam jumlah yang cukup. Oleh karena itu perusahaan harus melakukan usaha penjualan dan promosi yang agresif.

Konsep ini mengasumsikan bahwa konsumen malas atau enggan melakukan pembelian dan itu harus didorong, juga diasumsikan bahwa perusahaan memiliki cara penjualan dan peralatan promosi yang lebih efektif untuk merangsang pemnbelian. 


\section{ANALISA SISTEM YANG BERJALAN}

Berikut adalah kegiatan-kegiatan yang berjalan dalam perusahaan :

1. Marketing menerima permintaan produk dari pelanggan melalui email dan dan menetapkan persyaratan. Persyaratan yang ditentukan pelanggan yaitu, mutu produk, waktu penyerahan produk, penerimaan sales confirmation, penerimaan perubahan pada sales confirmation.

2. Marketing melakukan peninjauan terhadap persyaratan yang telah ditentukan pelanggan tersebut. Bila persyaratan yang ditentukan pelanggan tersebut dapat dipenuhi, maka persyaratan tersebut dituangkan ke dalam formulir bon order untuk digunakan sebagai sumber informasi bagi pelaksanaan proses produksi yang dimonitor oleh departemen PPC.

3. Apabila persyaratan yang diminta tidak dapat dipenuhi, maka hal ini akan dikonfirmasikan dengan pelanggan untuk mencapai kesepakatan. Setelah kesepakatan tercapai, maka persyaratan pelanggan dituangkan ke dalam formulir bon order.

4. Bon order dibuat oleh sales clerk, diperiksa oleh Sales Assistant, diketahui oleh Sales Manager dan disetujui oleh Marketing Director atau Sales Manager kalau yang bersangkutan berhalangan hadir.

5. Berdasarkan kesepakatan yang telah dicapai dengan pelanggan diterbitkan Sales Confirmation.dan dikirim kepada pelanggan. Produk jadi dikirim ke pelanggan dengan disertai surat jalan dan packing list yang dibuat oleh departemen PPC. Departemen QCF dan PPC akan memastikan bahwa quantity produk yang dikirim tidak melebihi batas toleransi yang tercantum pada table toleransi pengiriman kain jadi.

6. Bagian Billing dan Collection (departemen marketing) akan mengirimkan invoice (faktur penjualan) dan faktur pajak kepada pelanggan sesuai dengan produk yang telah dikirim. Bagian Billing dan Collection melakukan pemeriksaan atas pembayaran dari pelanggan pada bank yang telah disepakati antara pelanggan dengan marketing sales.

\subsection{Flowchart Sistem yang sedang Berjalan}

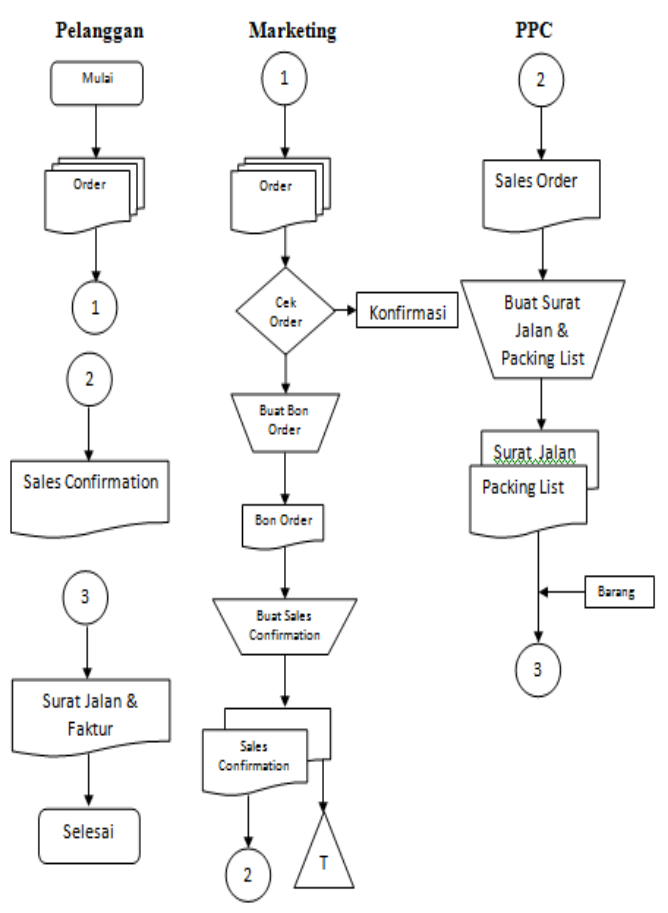

Gambar Flowchart Sistem yang Sedang Berjalan 
3.2 Diagram Konteks Sistem Yang Sedang Berjalan

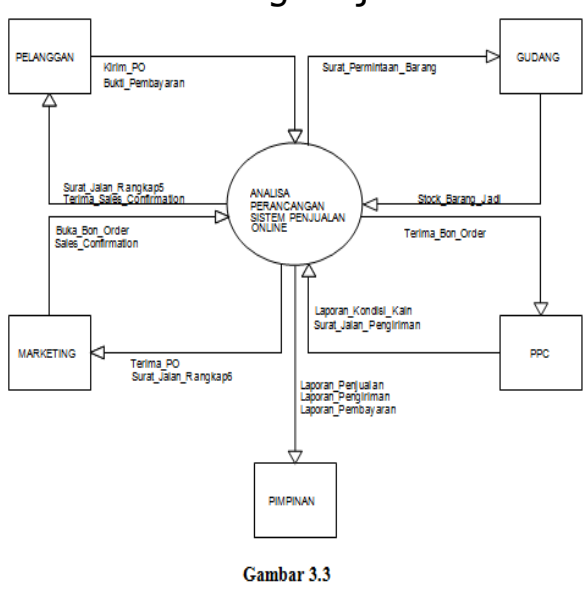

Gambar Diagram Konteks Sistem Yang Sedang Berjalan

Keterangan :

PO : Purchase Order (Order Pembelian)

3.3 Diagram Nol Sistem Yang Sedang Berjalan

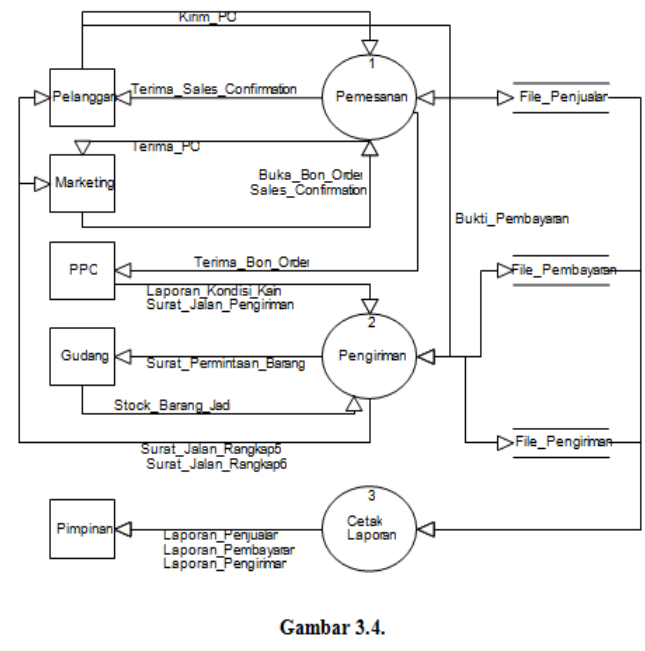

Gambar Diagram Nol Sistem Yang Sedang Berjalan Keterangan :

Po : Purchase Order (Order Pembelian

\subsection{Permasalahan yang Dihadapi}

Setelah penulis menganalisa sistem yang berjalan pada PT. Indo Taichen Textile Industry, maka penulis menemukan beberapa permasalahan yang dihadapi yaitu :

1. Jangkauan pemasaran yang masih kurang luas.
2. Media promosi yang digunakan kurang dapat mewakili semua produk yang dimiliki perusahaan.

3. Kurang dapat berkompetensi dengan pesaing lain yang telah memanfaatkan E-commerce dalam kegiatan usahanya, khusus pada media internet.

\subsection{Alternatif Pemecahan Masalah}

Dari hasil analisa system penjualan yang berjalan, maka penulis mengusulkan beberapa alternative pemecahan masalah, antara lain :

1. Melakukan promosi dengan menggunakan media elektronik.

2. Membangun sistem penjualan berbasiskan web, sehingga perusahaan dan produknya dapat dikenal oleh banyak orang.

3. Menciptakan proses transaksi pembelian yang cepat dan mudah.

Dari ketiga alternative tersebut, yang memungkinkan untuk dilakukan adalah membuat sistem penjualan berbasis web, karena sistem ini dapat mengurangi kelemahan yang ada dari system penjualan yang sedang berjalan.

\section{RANCANGAN SISTEM YANG DI USULKAN}

\subsection{Diagram Aliran Data (DAD)}

4.1.1 Diagram Konteks Sistem yang Diusulkan

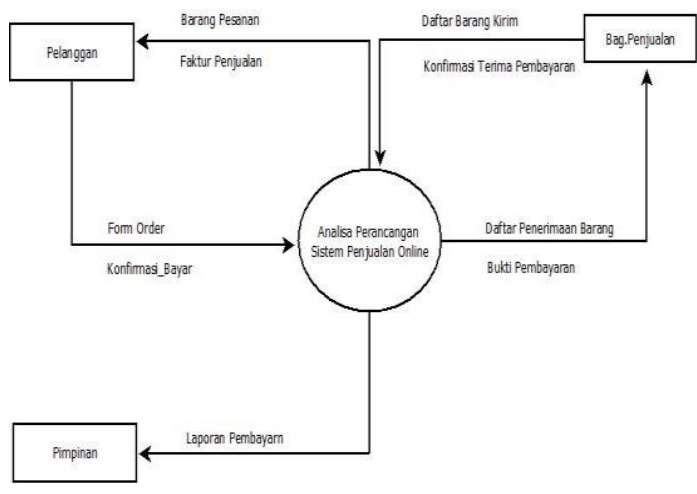

Gambar Diagram Konteks Sistem yang Diusulkan 
3) Diagran Rinci Proses 3.0

Diagram Nol Sistem yang Diusulkan

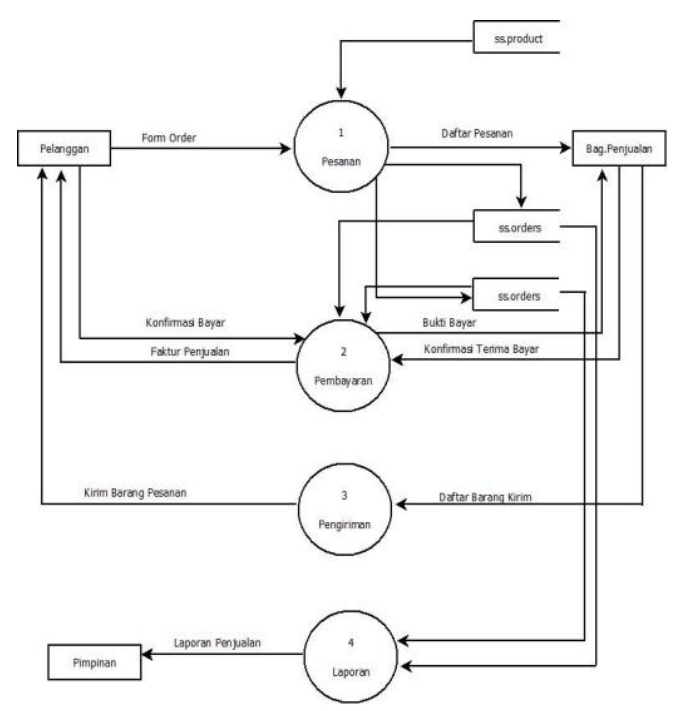

Gambar Diagram Nol Sistem yang Diusulkan

\subsubsection{Diagram Rinci}

1) Diagran Rinci Proses 1.0

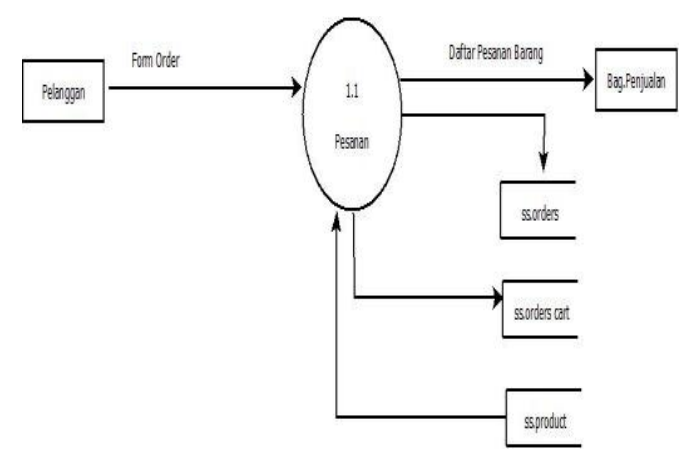

Gambar Diagram Rinci 1.0

\section{2) Diagran Rinci Proses $\mathbf{2 . 0}$}

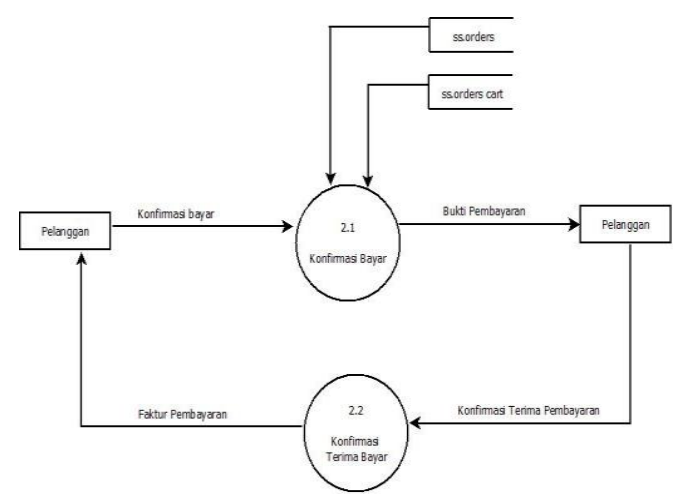

Gambar Diagram Rinci 2.0

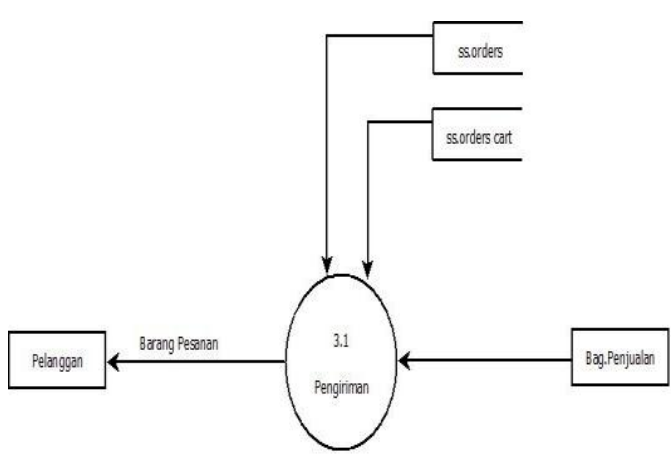

Gambar Diagram Rinci 3.0

\subsection{Rancangan Masukan (Input)}

\subsubsection{Rancangan Dokumen/For- mulir yang digunakan seba- gai input data}

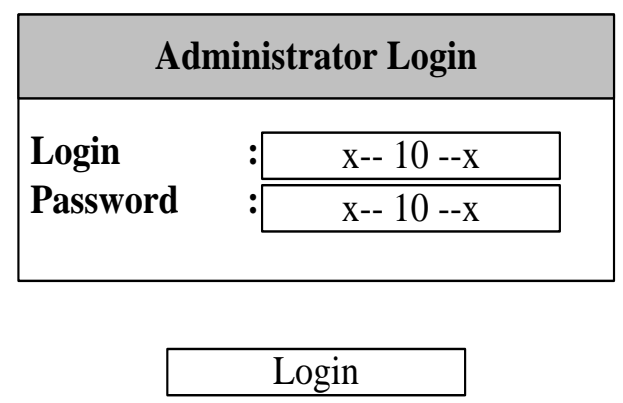

Gambar Rancangan Masukan Menu Login

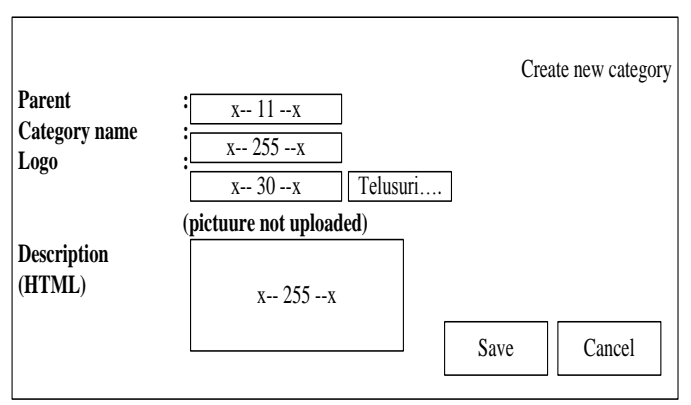

Gambar Rancangan Masukan Master Barang 


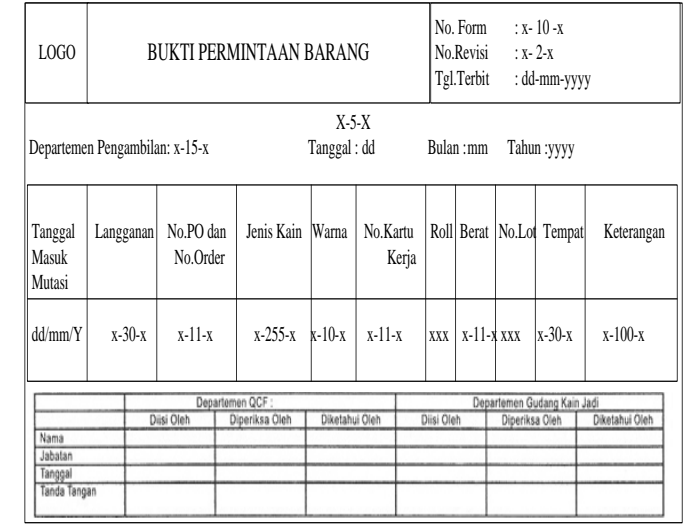

Gambar Rancangan Masukan Bukti Permintaan Barang

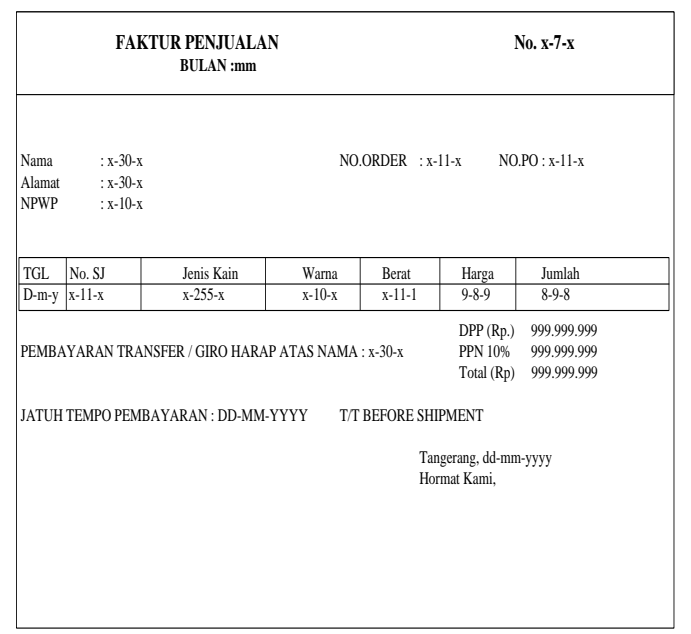

Gambar Rancangan Masukan Faktur Penjualan

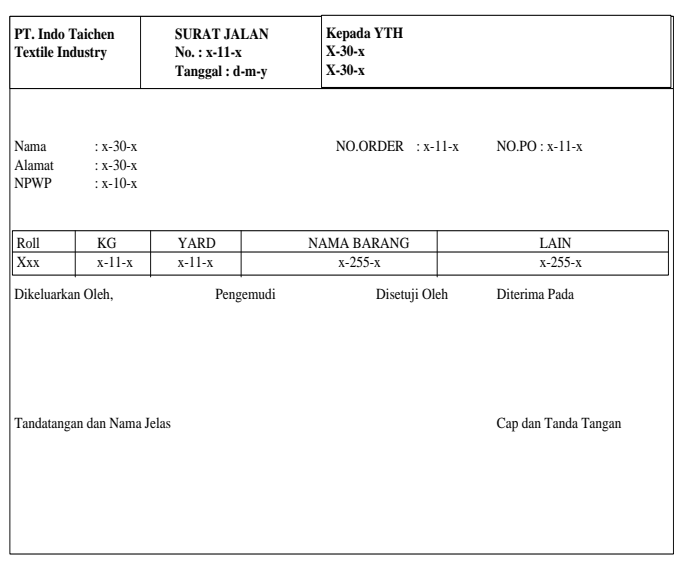

Gambar Rancangan Masukan Surat Jalan

\subsection{Rancangan Layar Input / Desain Tampilan Layar}

\section{Tampilan Utama Program}

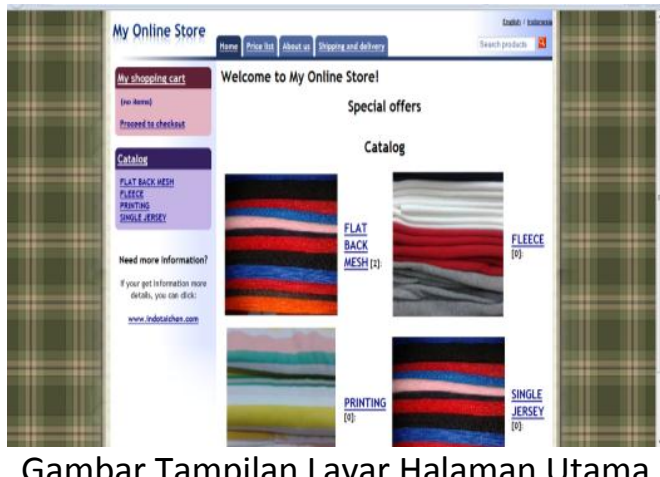

Pada menu ini ditampilkan layar halaman utama dimana pelanggan saat mengakses web dapat melihat langsung dan memilih jenis kain yang diinginkannya.

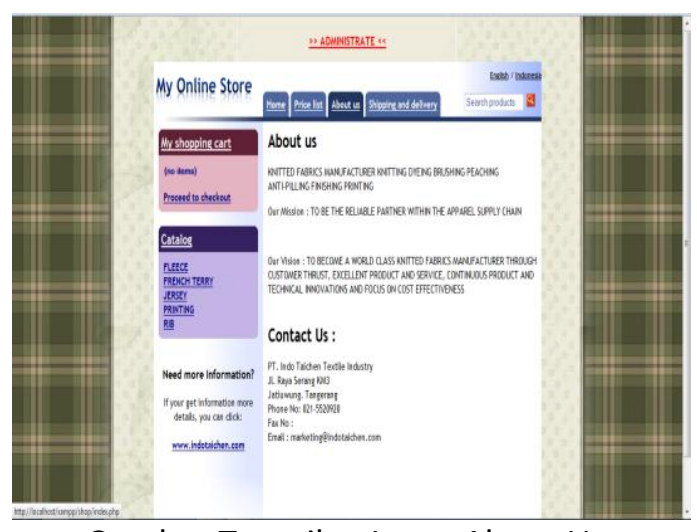

Gambar Tampilan Layar About Us

Pada tampilan about us memberikan pengenalan tentang perusahaan beserta visi dan misi perusahaan.

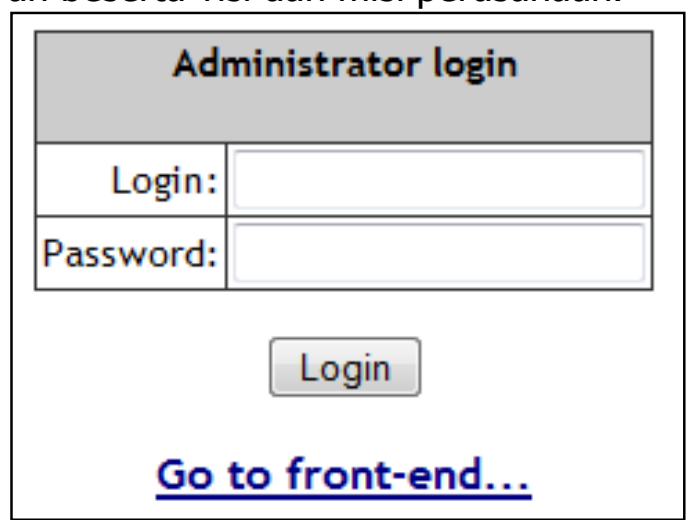

Gambar Tampilan Masukan Menu Login 
Pada tampilan menu login berfungsi apabila admin akan menambahkan suatu produk dan jenis kain baru ke dalam aplikasi web.

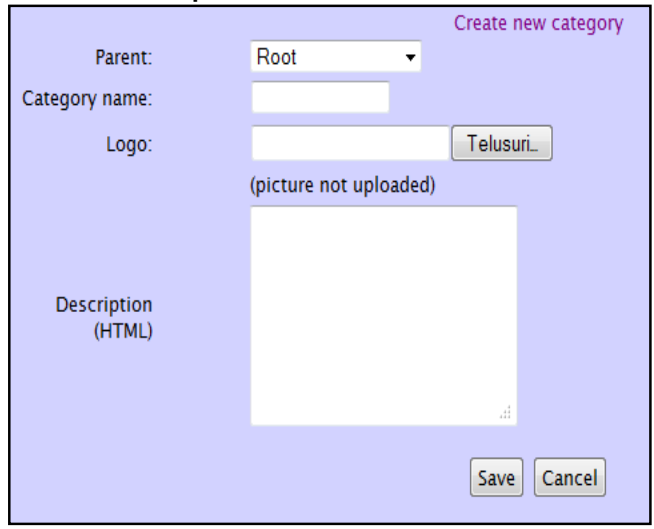

Gambar Tampilan Masukan Master Barang

Pada tampilan master barang berfungsi untuk menginput data barang baru yang akan berada dihalaman utama aplikasi. Data barang yang akan di input, yaitu jenis dan foto kain tersebut.

\subsection{Rancangan Keluaran (Output) 4.4.1 Laporan}

\begin{tabular}{|c|c|c|c|c|c|c|}
\hline PT. IND & \multicolumn{5}{|c|}{$\begin{array}{l}\text { LAPORANPENJUALAN } \\
\text { PerTanggal : dd-mm-yyyy s/d dd-mm-yyyy }\end{array}$} & \\
\hline \multicolumn{7}{|c|}{ Tgl.Cetak : dd-mm-yyyy } \\
\hline OrderID & Customer & \begin{tabular}{l|l|l} 
Email & Adress \\
\end{tabular} & Phone Number & Ordered Product & Order Total & Order Time \\
\hline$X-11-x$ & \begin{tabular}{c|c|}
$x-30-x$ \\
\end{tabular} & $x-30-x x x-30-x$ & 9-12-9 & $x-255-x x-11-x$ & $9-11-9$ & $\mathrm{~d}-\mathrm{m}-\mathrm{y}$ \\
\hline X-11-x & $x-30-x$ & $x-30-x \mid x-30-x$ & $9-12-9$ & $x-255-x-11-x$ & $9-11-9$ & $d-m-y$ \\
\hline$X-11-x$ & $x-30-x$ & $x-30-x \mid x-30-x$ & $9-12-9$ & $x-255-x-11-x$ & $9-11-9$ & $d-m-y$ \\
\hline \multicolumn{3}{|c|}{ Yang Mengetahui, } & \multicolumn{4}{|l|}{ Yang Membuat, } \\
\hline \multicolumn{3}{|c|}{ (Pimpinan) } & \multicolumn{4}{|c|}{ (Manager Peniualan) } \\
\hline
\end{tabular}

Gambar Rancangan Keluaran Laporan Penjualan

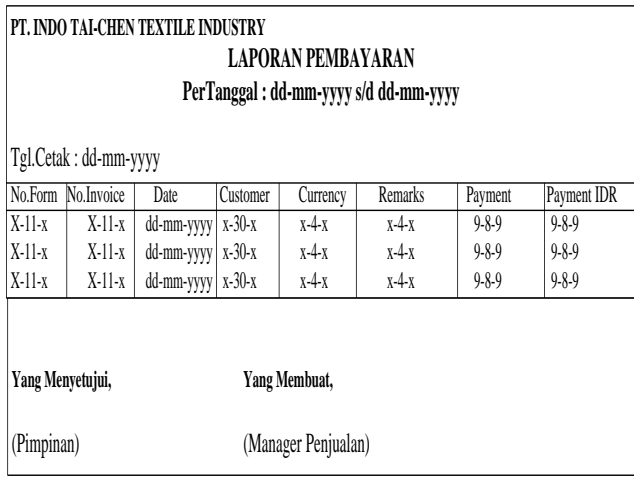

Gambar Rancangan Keluaran Laporan Pembayaran

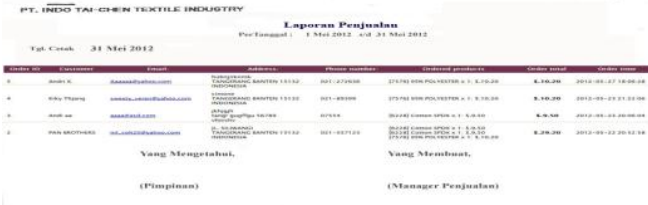

Gambar Tampilan Keluaran Laporan Penjualan

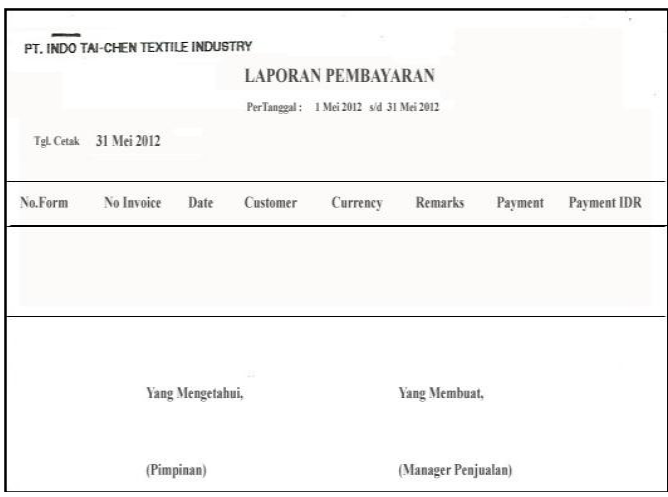

Gambar Tampilan Keluaran Laporan Pembayaran

\section{KESIMPULAN}

Berdasarkan penelitian yang dilakukan, dapat ditarik kesimpulan untuk Analisa perancangan sistem Penjualan Online pada PT. Indotaichen Textile Industry, adalah sebagai berikut:

1. Aplikasi yang dibuat merupakan program aplikasi berbasis web dari pengembangan sistem yang telah 
ada sebelumnya, yang bertujuan dan diharapkan dapat memudahkan perusahaan dalam menyampaikan informasi mengenai Penjualan Kain, profil, kegiatan usaha sampai dengan kinerjanya di pada PT. Indotaichen Textile Industry secara cepat, lengkap dan akurat.

2. Sistem yang telah dibuat dapat mempromosikan produk yang dipesan secara online melalui internet sebagai media publikasi.

3. Costumer (user) dapat dengan mudah mendapatkan informasi produk secara cepat, lengkap dan akurat.

\section{REFERENSI}

Aliminsyah. (2010). Kamus Istilah Akuntansi. Irama Widya, Bandung.

Burch, John, Gary Grudnitski (2010). Information Systems Theory and Practice, Edisi 4, Terjemahan Jogiyanto Hartono,MBA, Ph.D, Penerbit And Offset.

Kenneth E.Kendall dan Julie E.Kendall (2010). Analisis dan Perancangan Sistem. Jilid 1. Terjemahan Thamir Abdull Hafedh AlHamdany B.Sc., M.Sc. Penerbit Indeks.

McFadden, (2010), Sistem Informasi Konsep dan Aplikasi, Terjemahan Agus Mulyanto, Cetakan Pertama. Penerbit Pustaka Pelajar.

Muhamad, H. Fakhri ( 2010 ). Sistem Informasi Manajement, Edisi
Revisi, Cetakan Pertama, Unit Penerbit dan Percetakan AMPYKPN, Yos.

Mulyanto, Agus (2010). Sistem Informasi Konsep dan Aplikasi, Cetakan Pertama. Penerbit Pustaka Pelajar.

Raharjo, Budi, Imam Haryanto, Enjang RK (2012). Pemrograman WEB (HTML, PHP, \& MYSQL), Cetakan Kedua: Juni 2012 (Edisi Revise)

Raymond, McLeod,. JR. ( 2010 ). System Informasi Management, Jilid 1. Terjemahan Ali Akbar Yulianto. Penerbit Salemba 4, Jakarta.

Schell, P.George (2010). System Informasi Management, Jilid 1. Terjemahan Afia R.Fitriati, Penerbit Salemba 4, Jakarta

Yuardon (2010), Sistem Informasi Konsep dan Aplikasi, Terjemahan Agus Mulyato, Cetakan Pertama. Penerbit Pustaka Pelajar. 